\title{
A CONSTRUÇÃO DE SIGNIFICADO NA HIPERMÍDIA
}

\section{THE CONSTRUCTION OF MEANING IN HYPERMEDIA}

\author{
Luiz Roberto Carvalho ${ }^{1}$, M. Sc. \\ Alice Theresinha Cybis Pereira ${ }^{2}, \mathrm{PhD}$.
(1) Universidade Federal de Santa Catarina (UFSC) e-mail:semprecarvalho@gmail.com \\ (2) Universidade Federal de Santa Catarina (UFSC) \\ e-mail: acybis@gmail.com
}

Hipermídia, Ciberespaço, Ambientes Interativos

\begin{abstract}
A hipermídia é uma forma híbrida de representação e comunicação resultante da comunhão de processos indissociáveis, mesclados, mas distintos - o sonoro, o visual e o verbal. Com base na sua tríade, formada por som, imagem, e hipertexto -, é possível assinalar os ambientes interativos como um análogo da linguagem, porém, expresso num nível tecnológico superior. Essa perspectiva valida a hipermídia como um meio de comunicação que se assemelha às formas mais primitivas de interação humana, conferindo as interfaces digitais como dispositivos capazes de estabelecer relações cognitivas que independem da perspectiva linguística para que a comunicação ocorra. O presente estudo objetiva pontuar o fenômeno da comunicação na hipermídia, caracterizando suas correspondências sensoriais, estruturais e tecnológicas, a partir de uma abordagem sistêmica da sua morfologia, que é composta pela sintaxe, forma e discurso. Nesse sentido, ao perspectivar a hipermídia numa visão holística, é possível verificar a sinergia e a co-dependência pertinente aos seus processos e componentes.
\end{abstract}

\section{Hypermedia, Cyberspace, Interactive Environments}

Hypermedia is a hybrid form of representation and communication resulting from the communion of inseparable, merged, but distinct processes - sound, visual and verbal stimuli, represented by hypertext. Based on its triad, formed by sound, image, and hypertext, it is possible to point the interactive environments as an analogue of language, but expressed at a higher technological level. This perspective validates hypermedia as a means of communication that resembles the most primitive forms of human interaction, pointing the digital interfaces as devices that can establish cognitive relations that does not need the linguistic perspective to communicate. The present study aims to characterize the communication phenomenon in hypermedia, characterizing its sensorial, structural and technological correspondences, from a systemic approach of its morphology, that is composed by syntax, form and discourse. In this sense, when looking at hypermedia in a holistic view, it is possible to verify the synergy and co-dependence pertinent to its processes and components. 


\section{$16^{\circ}$ \\ ERGODESIGN USIHC CINAHPA}

\section{A Linguagem Pré-Discurso dos Ambientes Interativos}

Utilizando-se dos mais variados recursos acerca da língua e da linguagem, o homem vem, cada vez mais, criando meios para suprir suas necessidades de se comunicar e interagir com o mundo que o cerca, e assim ampliar seus conhecimentos. [GALLI, 2010] coloca que cada tipo de linguagem apresenta sua natureza, manifestando-se por diferentes tipos de elementos linguísticos e, através deles, extralinguísticos ${ }^{1}$, apontando suas características e especificidades, que são passíveis de reconhecimento. Grande parte dos avanços tecnológicos está no processo evolutivo da comunicação, conduzindo-se para uma maior democratização da informação, e, consequentemente, do saber.

A linguagem dos gestos 2 é considerada a primeira ferramenta de comunicação do homem, enquanto o discurso é definido como um recurso secundário. A comunicação não verbal é popular, por exemplo, em cenários como o diálogo entre mães e seus recém-nascidos, na comunicação com animais, e em ambiente de idioma desconhecido, pois atua no reforço da capacidade de persuasão de expressões, e nas demais situações quando a voz não funciona como única ferramenta comunicativa. De maneira geral, pode-se dizer que o objetivo da ação comunicativa está na transferência de mensagens compatíveis para a criação de uma linguagem comum, a fim de alcançar uma compreensão mútua entre emissor e receptor.

[BRESKIN, 2010] aponta que a cultura humana se originou a partir do surgimento de sinais e sistemas de signos - a linguagem. $\mathrm{O}$ autor se refere à linguagem como um modo de acumulação de informação exclusivamente peculiar à sociedade humana. Assim, a cultura humana foi aceita como um sistema secundário (o sistema primário é a

\footnotetext{
${ }^{1}$ Diz respeito aos aspectos não relativos ao sistema linguístico ou à linguística, tais como o gesto, o olhar, a postura. Em suma, às ações direcionadas a um objetivo de comunicação [DASCAL, 2006].

${ }^{2}$ Linguagem corporal e entonações de voz representam recursos completos de informações transferidas [GALLI, 2010].
}

linguagem natural, não apreendida) e desenvolvida através de uma combinação de signos e linguagem por conta da capacidade biológica do ser humano para identificar sinais e sistematizá-los linguisticamente. Enquanto adquiria os conceitos básicos da linguagem, o homem antigo transferia informações para sua tribo representando objetos reais através de desenhos, e referindo-se a eles através de movimentos imitativos, como na dança, ou pela emissão de sons, através da música. Etimologicamente, tais manifestações folclóricas, como arte visual, música e dança, remetem, portanto, a objetos, sons e cenários vivenciados pelo homem primitivo:

"Nas sociedades orais, as informações eram consumidas na mesma esfera espaço-temporal em que eram produzidas, razão pela qual os anciãos eram considerados depositários vivos da memória social, pois, através deles, as informações poderiam ser consumidas em momentos posteriores à sua produção" [ALZAMORA, 2007, p.76].

Ao aplicar a mecânica de formação de símbolos (em tradução livre) proposta por [BRESKIN, 2010], chega-se à seguinte constatação: através da descrição de um objeto por meio de movimentos e gesticulações, com o uso de representações gráficas, como desenho, e expressão vocal, cria-se um sinal complexo multimídia, um símbolo. Este sinal complexo é um conceito que, exposto a um processo de homogeneização (ou nivelamento) para que haja sua circulação prática, perde alguns de seus elementos excessivos, e gradualmente transforma-se num sinal vocal. Posteriormente, esse sinal vocal integra-se ao discurso linguístico e passa a ser representado através de uma palavra.

Conclui-se então que a transição de signos complexos para o discurso verbal foi um longo processo psicolinguístico de abstração da "consciência pictórica" e da semiótica corporal para sinais fonéticos sobre as bases de denominações de sons disponíveis que, por sua vez, começaram a desempenhar um papel ativo na formação de palavras. Nesse contexto, o processo de vocalização que definiu o som como uma ferramenta básica de comunicação influenciou significativamente na validação do mundo como um todo, pois possibilitou o surgimento das 


\section{$16^{\circ}$ \\ ERGODESIGN USIHC CINAHPA}

relações interpessoais através da linguagem. A partir desta etapa, a criatividade oral ganhou seu sentido verdadeiro e pleno. Num período em que o discurso foi envolvido em muitas funções de troca de informações, o homem antigo alcançou uma nova experiência estética com o uso habitual dos fundamentos expressivos da língua. Os modos de percepção ${ }^{3}$, transferência e armazenamento de informações foram otimizados, e tornou-se possível o registro e o resgate de distintas manifestações folclóricas (gestos, linguagem corporal e sons) de maneira sistemática e ordenada, através da linguagem.

Nessas novas configurações comunicativas, $o$ homem desenvolveu-se prioritariamente em torno do signo verbal, subordinando a ele diferentes classes de signos - da visualidade, da sonoridade, da espacialidade e da cinética. Desse modo, as formas de representação gráfica, musical e corporal mantiveram-se num status de realidade primária até o momento em que deixam de ser utilizadas devido ao pleno desenvolvimento e distribuição de uma linguagem de expressão vocal. Sendo a linguagem o principal sistema de modelação da cognição, imagem, música e dança, gradualmente desenvolveram-se como arte ${ }^{4}$, não sendo mais dedicados às suas históricas funções linguísticas, passando a ser considerados elementos pré-linguísticos.

Esta multimedialidade expressiva no período prédiscurso nos permite traçar um paralelo com a dinâmica da Interação Humano-Computador, e assim contextualizar a interatividade nos ambientes digitais. Com base nos componentes da sua tríade -

\footnotetext{
3 Do latim perceptio, percepção é a organização, identificação e interpretação de informações sensoriais, a fim de gerar uma representação mental através de um processo de transdução, no qual sensores no corpo humano transformam sinais do ambiente em sinais neurais codificados. Este processo de atividade neural cíclica utilizase de estímulos físicos e molda-os em relação à memória, expectativa e aprendizagem individual [SCHACTER 2011].

4 A arte pode ser considerada um sistema secundário - em outras palavras, um análogo da realidade, traduzido para o sistema principal da linguagem através de signos.
}

imagem, movimento e som -, é possível assinalar os ambientes digitais interativos como um meio análogo de linguagem pré-linguística expresso num nível tecnológico superior. Essa perspectiva valida a hipermídia como um meio de comunicação que se assemelha às formas mais primitivas de interação humana, assinalando as interfaces ${ }^{5}$ digitais como dispositivos capazes de estabelecer relações cognitivas que independem da perspectiva linguística para que a comunicação ocorra.

\section{Hipermídia e Ciberespaço}

Como um dos mais tradicionais meios de expressão da linguagem, os livros têm sido o método primário para fornecer informação. Sua estrutura interna tem se mantido a mesma, consistindo-se em índice, capítulos, glossário. Com o surgimento das interfaces digitais, permitiu-se que a informação fosse reestruturada em sistemas que estão mais próximos do que os livros da maneira como processamos as informações recebidas por nossos órgãos sensoriais. Nesse contexto, o fenômeno da Interação HumanoComputador possibilita experiências de engajamento sensorial que otimizam as habilidades humanas de acessar e processar informações.

O ciberespaço é um contexto complexo no qual ocorrem relações que envolvem a troca de informação e conhecimento, sendo considerado como todo e qualquer espaço informacional multidimensional que, dependente da interação do usuário, o permite acessá-lo, manipulá-lo, e transformá-lo através do intercâmbio de seus fluxos codificados de informação. A tradução desse espaço em ambientes navegáveis é a hipermídia, definida como uma linguagem a partir da qual se torna possível propor aos usuários novas formas de comunicação e novos paradigmas cognitivos. Em uma definição sucinta, [SANTAELLA, 2009, p. 48] conceitua hipermídia como "a integração, sem suturas, de dados, textos, imagens, e sons, dentro de um único ambiente de informação digital".

\footnotetext{
5 De acordo com [CAVALCANTE, 2010, p.200], "por interface entende-se a superfície de acesso e troca de informação".
}

Realização:

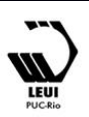




\section{$16^{\circ}$ \\ ERGODESIGN USIHC CINAHPA}

Dentre as principais características da hipermídia tem-se a possibilidade de apropriar-se de distintas linguagens, processos, códigos e mídias. Essa hibridizaçãa $o^{6}$ requer uma reorganização do modelo cognitivo do usuário, como aponta [SANTAELLA, 2009, p. 37] ao afirmar que "a navegação no ciberespaço e em outros ambientes hipermídia envolve a transformação perceptivo-cognitiva do leitor tradicional". Na prática, hibridizar linguagens significa, por exemplo, criar interfaces que possuam imagens, textos e sons, de modo que a soma destes elementos resulte na formação de uma unidade semântica. Esta mistura de linguagens possibilita ao usuário uma "leitura sinestésica" ligada não somente à mensagem proposta, mas também ancorada ao seu repertório de experiências culturais e sensoriais. Por utilizar distintas mídias, a hipermídia pode ser descrita como um agrupamento de subprojetos que podem passar desde a simples criação de um texto à elaboração complexa de animações e vídeos interativos, baseados em realidade virtual ${ }^{7}$ :

\footnotetext{
${ }^{6} \mathrm{O}$ significado de híbrido tem sua origem no campo da biologia e define o indivíduo resultante do cruzamento de duas espécies diferentes. Analogamente, no contexto das linguagens aplicadas ao ciberespaço, o hibridismo passa a ser o termo que melhor define a miscigenação de linguagens, sejam estas visuais, verbais e sonoras, que se fazem presentes em ambientes interativos [SANTAELLA, 2009].
}

7 Realidade Virtual (RV) pode ser definida como um sistema informático capaz de criar um universo simulado dentro do qual o usuário tem a impressão de estar manipulando objetos físicos reais. Trata-se de um sistema que permite ativar percepções humanas ao ponto de produzir o mais alto grau de imersão sensória no ambiente simulado. A realidade virtual se constitui na extensão máxima do ciberespaço [SANTAELLA, 2009]. Nesse contexto, [Blauert, 2006] enfatiza que o significado da palavra "virtual" é muitas vezes erroneamente interpretado como "fictício". O significado original da palavra é, no entanto, "existente em termos de seu poder", ou seja "eficaz" (do latim virtus, que significa energia, potência). Se uma realidade virtual, ou mesmo uma realidade real é tomada como ilusória ou real, esta depende da percepção do observador. Para o autor, um ambiente é tomado como verdadeiro quanto mais o observador é exposto a este e assim adquire uma sensação de imersão e presença (por presença, entenda-se a sensação de fazer parte deste ambiente). $16^{\circ}$ Ergodesign - Congresso Internacional de Ergonomia e Usabilidade de Interfaces Humano Tecnológica: Produto, Informações Ambientes Construídos e Transporte

$16^{\circ}$ USIHC - Congresso Internacional de Ergonomia e Usabilidade de Interfaces Humano Computador

CINAHPA | 2017 - Congresso Internacional de Ambientes Hipermídia para Aprendizagem.

"Quando o usuário "pilota” o computador, ele está sempre dentro de um espaço informacional, um ambiente de signos híbridos no qual imagens, gráficos, desenhos, figuras, palavras, textos, sons e mesmo vídeos misturam-se na constituição de uma metamídia. Ora, a profusão híbrida de signos que povoam as telas não é uma profusão aleatória. Essa profusão está estruturada em nexos (links) ou atalhos, que, uma vez acionados, levam o usuário a saltar de uma página a outra, de um campo a outro, de uma informação a outra. [...] Isso é chamado de hipermídia, a linguagem própria dos ambientes informacionais que foram batizados no ciberespaço" [SANTAELLA, 2009, p.144-145].

Diferentemente de estruturas lineares que implicam na continuidade e têm início e fim delimitados, interfaces híbridas propõem ambientes nos quais as informações são dispostas de forma a possibilitar que o discurso ocorra em várias direções. Este fluxo de informação ocorre numa estrutura ramificada e não sequencial por meio do hipertexto, e está diretamente relacionado à navegação ${ }^{8}$, visto que é através dos links propostos nas estruturas hipertextuais que o usuário se move nos ambientes interativos:

"Em vez de um fluxo linear de texto como é próprio da linguagem verbal impressa, no livro particularmente, o hipertexto quebra essa linearidade em unidades ou módulos de informação, consistindo de partes ou fragmentos de textos. Nós e nexos associativos são os tijolos básicos de sua construção. Os nós são as unidades básicas de informação em um hipertexto" [SANTAELLA, 2009, p.50].

O hipertexto é o elemento básico da linguagem da hipermídia, e através do link, ou nó, que é sua unidade de estrutura de informação, constitui-se numa forma fragmentada e descentralizada de distribuição de informação. A navegação nos ambientes hipermidiáticos se constrói por percursos através de sequências de links, na forma

\footnotetext{
8 [Garret, 2011] define o design de navegação como uma forma especializada de design de hipermídia destinado à apresentação de espaços de informação, apontando que o mesmo deve cumprir com três objetivos simultâneos: a) fornecer aos usuários um meio para ir de um ponto a outro; b) comunicar a relação entre os elementos da interface; c) comunicar a relação entre o conteúdo e a página que o usuário está visualizando no momento.
}

Realização:

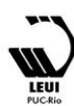




\section{$16^{\circ}$ \\ ERGODESIGN USIHC CINAHPA}

de textos, imagens, sons, vídeos, sendo que há uma lógica de conexão e coerência percebida pelo usuário cumulativamente no decorrer de sua trajetória. Como resultado, o papel do usuário torna-se cada vez mais ativo, tendo em vista que uma diversidade de caminhos sobre a informação pode ser tomada, e a maneira como o conteúdo é disponibilizado pode ser controlada.

Ao relacionar unidades de informação de natureza distinta (imagética, sonora e verbal) numa estrutura interativa, a malha hipertexual cria um paradigma cognitivo que ultrapassa as possibilidades oferecidas pelos gêneros multimodais tradicionais. Esse potencial comunicativo diferenciado pode favorecer a construção de mensagens através da utilização de distintas modalidades sensoriais, favorecendo assim a apreensão de uma mesma informação por usuários com modelos cognitivos distintos. Sendo a hipermídia o resultado da combinação consistente e equilibrada de elementos hipertextuais e multimidiáticos, a eficácia da comunicação neste meio deve-se principalmente à capacidade de articulação, superposição e combinação dessas linguagens:

“[...] no ciberespaço existem processos de inferência e raciocínio que funcionam como rotas mentais condutoras da atividade de navegação. Esses processos inferenciais são inseparáveis da riqueza sensorial das linguagens multimidiáticas que são próprias da hipermídia, na sua junção do verbal, do visual, e do sonoro. Isso traz como consequência a indissolubilidade entre a sinestesia, vários sentidos sendo estimulados ao mesmo tempo, a consequente densidade perceptiva e as complexas atividades mentais" [SANTAELLA, 2009, p. 131].

\subsection{O Design de Hipermídia}

O desenvolvimento de um projeto de hipermídia é um processo complexo, evidenciado principalmente pela interdisciplinaridade pertinente ao processo. [BAETA NEVES, 2006] coloca que, para comunicar, a hipermídia necessita engajar seu público em sua própria dinâmica de virtualidades. A interface deve estabelecer relações formais e funcionais que tornem possível prever a configuração e a organização de informações verbais, visuais, sonoras, sinestésicas, de interação e navegação. [MOURA, 2003, p.159] elucida tal constatação, ao conceituar design de hipermídia como:

“[...] uma atividade que diz respeito à aplicação e ao conhecimento de diferentes linguagens de expressão e de comunicação e suas possibilidades de inter-relação. Lida com diferentes tipos e procedências de imagens, textos e sons, onde é necessário o domínio e conhecimento dos procedimentos e elementos projetuais, técnicos e tecnológicos, bem como as relações e questões do ciberespaço e as pertinentes ao usuário."

A consolidação do ciberespaço representa uma mudança de paradigma no processo de formação dos profissionais que atuam na produção de sistemas interativos e exige uma releitura das habilidades que lhes são ofertadas no ambiente acadêmico. [BORTOLATO et al, 2010] aponta que a partir da última década, a discussão dos conceitos de complexidade e de interdisciplinaridade passou a ganhar destaque entre os educadores. Dada sua capacidade de associar diferentes meios e informações, a hipermídia foi considerada idealmente adequada para fomentar a interdisciplinaridade, promovendo uma articulação dos saberes em toda sua extensão e complexidade:

"No cenário atual de convergência entre as mídias, profissionais com diferentes perfis têm sido forçados a dar um passo adiante. Enquanto os produtores de vídeo estão entrando na área de autoração, território "nativo" dos programadores de software, por causa do surgimento do DVD, os profissionais de áudio estão incorporando funções como edição e captura de imagens. [...] Estes fatos representam uma ruptura e, ao mesmo, uma diluição entre as fronteiras tradicionais do que chamamos de "produtora de vídeo", "produtora de áudio", e "produtora de hipermídia". Em algum grau, todas essas empresas estarão vinculadas ao conceito de hipermídia. Isso não quer dizer que todas elas farão todo tipo de trabalho [...] O que muda é que haverá intersecções maiores entre as áreas de atuação das diversas empresas. [...] E qual é o impacto de todas essas transformações no processo de produção de conteúdos audiovisuais para sistemas hipermidiáticos? Em primeiro lugar, muda o perfil do profissional que, cada vez mais, precisa estar familiarizado com diversas linguagens" [SHUM, 2009, p.135-136].

Nesse contexto, ao perspectivar o projeto de design
Realização:

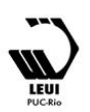




\section{$16^{\circ}$ \\ ERGODESIGN USIHC CINAHPA}

de hipermídia numa visão holística, e pontuar a sinergia e a co-dependência pertinente aos seus processos, tem-se uma visão projetual abrangente, que expande o espectro das suas componentes, e expõe o projeto hipermidiático como a soma de todos os seus elementos constituintes.

\subsection{A Construção de Significado nos Ambientes Interativos}

Na medida em que participa diretamente de um processo de comunicação, a linguagem da interface pode ser comparada com a linguagem natural, tanto em função comunicativa quanto em estrutura, como um sistema em evolução composto de elementos e inter-relacionamentos. A construção deste signo híbrido processa-se em uma tríade composta pela sintaxe, forma e discurso. A sintaxe lida com a combinação de diversos elementos, como textos, figuras, cores e sons. Desse modo, a sintaxe pressupõe a existência de elementos (objetos) a serem combinados. Ao traçar esses elementos (sonoros, imagéticos e linguísticos) em uma composição, adquire-se uma forma. Esta nada mais é que a harmonização da sintaxe, expressa na dimensão da interface. Esta forma cria uma mensagem, que, através dos links, confere-lhe uma narrativa, constituindo-a como um discurso, ou argumento.

Nesse contexto, interfaces são apenas fragmentos, são recortes pelos quais a navegação traça uma ordem, e dá-lhes um sentido. É na navegação, portanto, que a característica do discurso mostra-se evidente. A arbitrariedade do link, ao associar uma interface à outra, é o que respalda a construção de um discurso, e confere a hipermídia uma linguagem própria. [SANTAELLA, 2001, p.115] assevera que o " [...] traço mais característico do signo linguístico está na sua arbitrariedade e convencionalidade", pois sem a arbitrariedade do hiperlink, as interfaces são elementos isolados, que podem ou não ter relações entre si, sendo apenas fatos brutos, eventos particulares.

O hibridismo sígnico ocorre na hipermídia através de uma troca entre os princípios lógicos que regem suas três matrizes de linguagem: sonora, visual e verbal. Estas linguagens se combinam por meio da $16^{\circ}$ Ergodesign - Congresso Internacional de Ergonomia e Usabilidade de Interfaces Humano Tecnológica: Produto, Informações Ambientes Construídos e Transporte

$16^{\circ}$ USIHC - Congresso Internacional de Ergonomia e Usabilidade de Interfaces Humano Computador

CINAHPA | 2017 - Congresso Internacional de Ambientes Hipermídia para Aprendizagem.

sintaxe de seus elementos, constituindo uma composição através de uma forma que, por meio do hipertexto, traça um discurso. O que se desenvolve nesse contexto é um emaranhado de intersemioses, um encadeamento de intercâmbios sígnicos dos elementos da sintaxe na confecção de uma forma que, organizada, caracteriza o discurso. Entender a construção dessa complexidade intersemiótica e como esta interage com o usuário é fundamental para o desenvolvimento de interfaces ricas em potencialidade de significação.
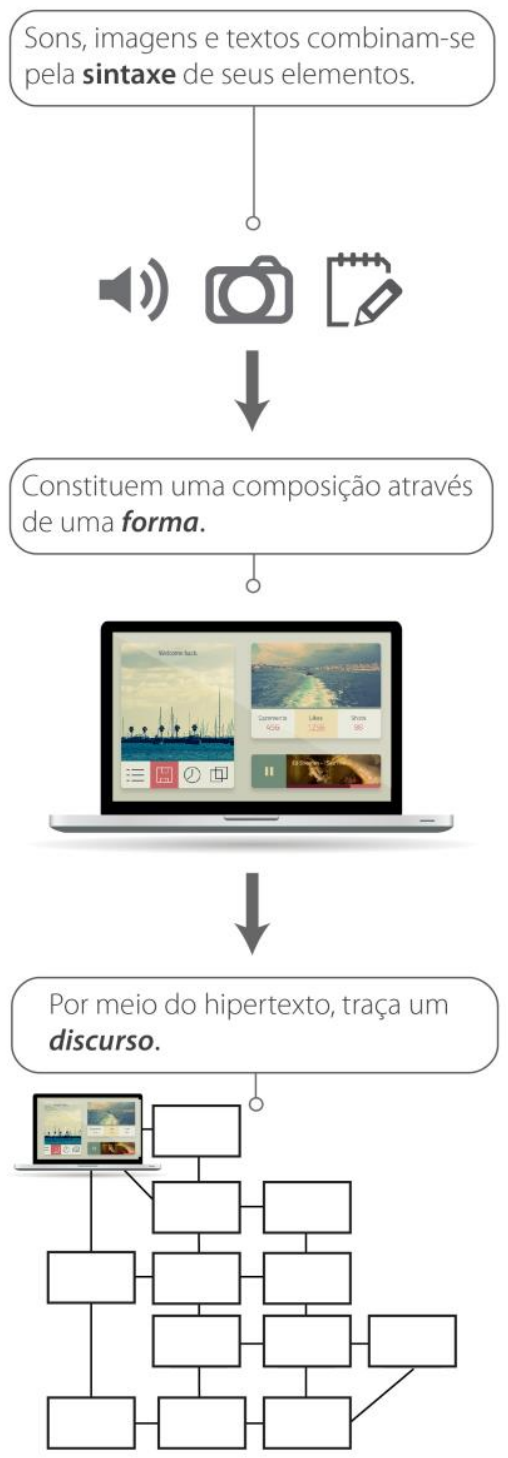

Figura 1: Hibridismo da interface expresso através das matrizes da sintaxe, forma e discurso. 


\section{$16^{\circ}$ \\ ERGODESIGN USIHC CINAHPA}

A linguagem da hipermídia demanda uma organização que seja capaz de harmonizar todos os seus elementos e processos, de modo que as interfaces contemplem em totalidade suas distintas matrizes de linguagem, envolvendo as propriedades das linguagens sonora, visual e verbal. Nesse contexto, [MARTINEZ, 2004] assevera que a combinação de meios sonoros, imagéticos e textuais resulta em saltos de significação que não podem ser simplesmente descritos como uma adição. Essas combinações constituem sistemas sui generis que não se explicam pela soma de suas partes. Seguindo essa perspectiva, o que se constata é que unidade da hipermídia configura-se como sistêmica, isto é, há um conjunto de agentes com funções específicas que interagem e se integram na realização da obra.

[VIEIRA, 2007] aponta que existem três parâmetros classificatórios fundamentais para se observar um sistema': sua capacidade de permanência, seu meio ambiente e sua autonomia. Ainda dentro dessa perspectiva, para um sistema se consolidar como tal, existem parâmetros chamados hierárquicos ou evolutivos delineados, a saber: composição, conectividade, estrutura, integralidade, funcionalidade e organização, sendo todos permeados por um parâmetro que pode surgir desde o primeiro estágio, a complexidade. Assim, um sistema é caracterizado por seu processo temporal e sua capacidade de crescimento, sendo que a complexidade de tal movimento se dá pela diversidade de conexões que são realizadas em prol da sobrevivência do próprio sistema. Nesse contexto, abordar a hipermídia como um sistema de signos ${ }^{10}$ é perspectivá-la numa dimensão global, como substituto da realidade natural e como unidade integradora de subsistemas e códigos que, ao integrarem-se uns com os outros, perdem parcialmente sua autonomia de acordo com a função que realizam.

\footnotetext{
${ }^{9}$ [MEISTER, 1999] define sistema como uma entidade composta de elementos que trabalham juntos - interagem - de modo a atingir um objetivo que esses mesmos componentes não seriam capazes de produzir isoladamente.
}

${ }^{10}$ [QUEIROZ, 2010] assinala que um sistema semiótico é um sistema que produz, transmite e interpreta signos de diferentes tipos. $16^{\circ}$ Ergodesign - Congresso Internacional de Ergonomia e Usabilidade de Interfaces Humano Tecnológica: Produto, Informações Ambientes Construídos e Transporte

$16^{\circ}$ USIHC - Congresso Internacional de Ergonomia e Usabilidade de Interfaces Humano Computador

CINAHPA | 2017 - Congresso Internacional de Ambientes Hipermídia para Aprendizagem.
A hipermídia se apresenta como a articulação entre organização e complexidade, sendo que uma ordem complexa só existe se a conexão entre ordem e desordem existir. Para [LEÃO, 2002], há complexidade se houver simplicidade, ao exemplificar que as escolhas aleatórias do usuário só funcionarão se o sistema for previamente programado, determinando possíveis ligações a pontos específicos. Uma pesquisa não sequencial só é possível porque houve um trabalho prévio, necessariamente sequencial, e uma rota de navegação livre, criativa e fluida, fora, necessariamente, desenvolvida com precisão, rigor e obediência aos padrões necessários para tornar tais associações possíveis. A elasticidade dos sistemas hipertextuais, sua capacidade de expansão e retração, está diretamente ligada a uma construção firme, sintética, e blocos sólidos de informações.

Neste complemento organizacional entre ordem e desordem, simples e complexo, determinado e aleatório, sequencial e não-sequencial, livre e rígido, evidencia-se a dimensão da hipermídia. Este fenômeno pode ser facilmente observado nos caminhos da leitura hipertextual, como por exemplo, quando um usuário percorre um caminho complexo ao se deslocar entre os links a partir de um software navegador na web. Apesar da desordem no percurso, uma ordem oculta está presente, podendo ser encontrada através do comando histórico, que refaz a rota completa de navegação deste usuário. Desse modo, concebemse as noções de organização e complexidade dos sistemas como uma rota circular ad infinitum.

\section{Considerações Finais}

Um dos cuidados mais importantes que se deve ter com sistemas consiste em tentar analisá-los. Os sistemas devem ser entendidos como um todo que se articula e só existe como tal, tendo em vista que ao reduzi-lo às suas partes mais simples, decompondo-o, este não é mais concebido como um sistema. Daí o equívoco em analisar as componentes da interface isoladamente, negligenciando suas relações com os demais elementos do sistema. É através dos eixos lógicos da sintaxe, forma e discurso, e das propriedades 


\section{$16^{\circ}$ \\ ERGODESIGN USIHC CINAHPA}

$16^{\circ}$ Ergodesign - Congresso Internacional de Ergonomia e Usabilidade de Interfaces Humano Tecnológica: Produto, Informações Ambientes Construídos e Transporte

$16^{\circ}$ USIHC - Congresso Internacional de Ergonomia e Usabilidade de Interfaces Humano Computador

CINAHPA | 2017 - Congresso Internacional de Ambientes Hipermídia para Aprendizagem. das linguagens verbal, visual e sonora da interface que é possível compreender a hipermídia em totalidade. Nesse sentido, a complexidade do sistema demanda uma observação dos princípios organizativos que operam dentro de uma heterogeneidade formada por componentes específicos, mas que operam em sinergia.

\section{Referências Bibliográficas}

ALZAMORA, Geane Carvalho. Fluxos de informação no ciberespaço - conexões emergentes. Revista Galáxia, São Paulo, n. 13, p. 75-88, jun. 2007.

BAETA NEVES, Ana Q. Novos Encantamentos: Design de hipermídia enquanto design de engajamento. Dissertação de mestrado - PUCRio, 2006.

BLAUERT, Jens. Real Worlds, Virtual Worlds and the Roots of Psychoacoustics. 2nd

ISCA/DEGA Tutorial \& Research Workshop on Perceptual Quality of Systems, Berlim;

Alemanha, set., 2006.

BORTOLATO, Márcia Melo; PEREIRA, Alice T Cybis; GONÇALVES, Marília Matos. O uso de mapas conceituais no design educacional para o planejamento de hipermídia na educação a distância. In: Simpósio Hipertexto e Tecnologias na Educação. NEHTE/UFPE, 2010.

BRESKIN, Vladimir. Triad: Method for Studying the Core of the Semiotic Parity of Language and Art. Signs: International Journal of Semiotics. Royal School of Library and Information Science, Denmark, Vol. 3, pp. 1-28, 2010.

CAVALCANTE, Marianne Carvalho Bezerra. Mapeamento e Produção de sentido: os links no hipertexto. In: Hipertexto e Gêneros Digitais: novas formas de construção de sentido. Luis Antônio Marcuschi, Antonio Carlos Xavier (orgs.) - 3. ed., São Paulo: Cortez, 2010.

DASCAL, M. Interpretação e compreensão. São Leopoldo: Editora UNISINOS, 2006.
GALLI, Fernanda Correa Silveira. Linguagem da Internet: um meio de comunicação global. In: Hipertexto e Gêneros Digitais: novas formas de construção de sentido. Luis Antônio Marcuschi, Antonio Carlos Xavier (orgs.) - 3. ed., São Paulo: Cortez, 2010.

GARRETT, Jesse James. The elements of user experience: user centered design for the web and beyond. 2nd ed. Berkeley, California: New Riders, 2011.

LEÃO, Lucia. The Labyrinth as a Model of Complexity: The Semiotics of Hypermedia. COSIGN 2002, 02 - Computational Semiotics for Games and New Media. University of Augsburg, Lehrstuhlfür Multimedia-Konzepte und Anwendungen, Germany.

MARTINEZ, José Luiz. Semiótica da música na multimídia e hipermídia computadorizada. Projeto de pesquisa vinculado ao Programa de PósGraduação em Comunicação e Semiótica e a Faculdade de Comunicação e Artes do Corpo da PUC-SP. Ago, 2000. Disponível em:

http://www.pucsp.br/ cos/rism/projet-j.htm Acesso em: 13 set. 2015 .

MEISTER, D. The history of human factors and ergonomics. London: Lawrence Erlbaum, 1999.

MOURA, Mônica Cristina de. $O$ design de hipermídia. Tese (Doutorado), Pontifícia Universidade Católica de São Paulo, São Paulo, 2003.

QUEIROZ, João. Sistemas semióticos, artefatos cognitivos, Umwelt - uma contribuição ao Design da Informação. InfoDesign - Revista Brasileira de Design da Informação; Brazilian Journal of Information Design. v. 7, n. 2 [2010], p. 7 - 12. ISSN 1808-5377

SANTAELLA, Lucia. Matrizes da linguagem e pensamento - sonora, visual, verbal. São Paulo: Editora Iluminuras, 2001.

. Navegar no Ciberespaço: o perfil cognitivo do leitor imersivo. 3. ed., São Paulo: Paulus, 2009. 


\section{$16^{\circ}$ \\ ERGODESIGN USIHC CINAHPA}

$16^{\circ}$ Ergodesign - Congresso Internacional de Ergonomia e Usabilidade de Interfaces Humano Tecnológica: Produto, Informações Ambientes Construídos e Transporte

$16^{\circ}$ USIHC - Congresso Internacional de Ergonomia e Usabilidade de Interfaces Humano Computador

CINAHPA | 2017 - Congresso Internacional de Ambientes Hipermídia para Aprendizagem.

SCHACTER, D. Psychology. Worth Publishers, New York, 2011.

SHUM, Lawrence. O meio digital e a produção midiática. Cibertextualidades. vol. 3. p. 131-140. Ed. Universidade Fernando Pessoa. Porto, 2009.

VIEIRA, Jorge de Albuquerque. Ciência - Formas de Conhecimento: Arte e Ciência uma visão a partir da complexidade. 2a.ed.Fortaleza: Gráfica e Editora, 2007. 